\title{
ANÁLISE DO BIOFLUIDO SALIVAR PÓS-TERAPIA LED TRANSCUTÂNEA EM REGIÃO MASSETÉRICA - ESTUDO CLÍNICO
}

\author{
Vanessa Borelli Seefeldt ${ }^{1}$ \\ Leandro Junio Masulo \\ Davidson Ribeiro Costa ${ }^{3}$ \\ Renata Amadei Nicolau ${ }^{4}$
}

Resumo: O biofluído salivar (BS) é um líquido secretado por glândulas salivares (GS). Possui a capacidade de manter a homeostasia da cavidade bucal e regular funções importantes do sistema estomatognático. A Terapia Laser ou LED de Baixa Intensidade (TLBI) tem sido investigada na área da saúde visando à redução de fadiga e a biomodulação tecidual e muscular. Contudo, não foram evidenciados estudos que analisassem o fluxo salivar, pH e capacidade tampão quando a TLBI é empregada, de forma transcutânea, em locais próximos às GS. Deste modo, o presente estudo tem como objetivo analisar as características bioquímicas do BS pré e pós-irradiação com LED no músculo masseter. Para tal, foram selecionados 6 voluntários do gênero masculino dos quais foram coletadas e analisadas duas amostras de saliva total não estimulada (STNE) e estimulada (STE), antes e após as terapias (controle, placebo ou LED terapia). Não foram evidenciadas diferenças significativas $(p>0,05)$ entre as terapias avaliadas nos diferentes voluntários. Com base nos resultados é possível concluir que a irradiação LED não promoveu alteração nos parâmetros analisados.

Palavras-chave: Saliva; Glândula salivar; LED.

\footnotetext{
1 Odontologia/Universidade do Vale do Paraíba-Univap, Brasil. E-mail: neborelli@yahoo.com.br.

2 Odontologia/Universidade do Vale do Paraíba-Univap, Brasil. E-mail: I.masulo@hotmail.com.

3 Odontologia/Universidade do Vale do Paraíba-Univap, Brasil. E-mail: davidson@univap.br.

4 Odontologia/Universidade do Vale do Paraíba-Univap, Brasil. E-mail: rani@univap.br.
} 